\title{
O ATO DE CURTIR: A ESTANDARDIZAÇÃO DA RESPONSIVIDADE NO FACEBOOK
}

\author{
Artur Daniel Ramos Modolo* \\ Universidade de São Paulo \\ Departamento de Letras Clássicas e Vernáculas \\ São Paulo, SP, Brasil
}

\begin{abstract}
Resumo: O presente artigo analisa publicações feitas por páginas de divulgação científica brasileira no Facebook, tomando como base o conceito de responsividade proveniente da teoria bakhtiniana. Em virtude de as redes sociais disponibilizarem meios estandardizados e quantificáveis de formas responsivas, investiga parte das consequências produzidas por esse tipo de interatividade online. Concilia dados qualitativos e quantitativos do corpus analisado para produzir uma interpretação sobre o ato de curtir no Facebook. Como material, coletou todas as publicações, durante quatro meses, das páginas da Pesquisa FAPESP, Scientific American Brasil e Superinteressante. O resultado permite identificar características discursivas e temáticas dos posts que obtiveram maior repercussão entre os leitores, assim como estabelecer relações entre a leitura hipertextual, a web 2.0 e as formas responsivas produzidas nesse contexto.
\end{abstract}

Palavras-chave: Responsividade. Análise dialógica. Redes sociais. Estandardização. Facebook.

1 INTRODUÇÃO

I can't write without a reader. It's precisely like a kiss - you can't do it alone ${ }^{1}$.

(John Cheever)

A responsividade é um conceito fundamental para as reflexões da teoria bakhtiniana. Se, por um lado, todos os agentes sociais contam com uma consciência responsável e única, por outro, Bakhtin (2012) afirma ser inviável que a consciência individual se baste a si mesma. Ao proferir um enunciado, extrapolam-se as fronteiras puramente linguísticas da sintaxe frasal e dos modelos comunicativos de alternâncias de posições estáticas (falante e ouvinte) para se assumir um posicionamento axiológico e ideológico. Tal posição valorativa frente ao mundo é, concomitantemente, única e não isolada do seu entorno.

Nessa perspectiva, Bakhtin (2010b) afirma que o enunciado e o seu autor sempre reagem e estão à espera do discurso alheio, expresso por outra consciência, capaz de

\footnotetext{
* Doutor em Filologia e Língua Portuguesa pela Universidade de São Paulo (USP). Programa de PósGraduação em Filologia e Língua Portuguesa. Fomento à Pesquisa da Fundação de Amparo à Pesquisa do Estado de São Paulo (FAPESP) - Proc. 2013/09828-1. E-mail: adrmodolo@ gmail.com.

1 Tradução livre da língua inglesa para a língua portuguesa: Eu não posso escrever sem um leitor. É precisamente como um beijo - você não pode fazê-lo sozinho".
} 
avaliá-los e, de tal modo, preencher uma lacuna intrínseca de sua constituição. Embora, na transição entre o final do século XX e início do XXI, progressos científicos, comunicativos e tecnológicos tenham transcorrido, a complementaridade intersubjetiva segue a ser essencial para o engajamento dos agentes sociais em trocas discursivas diversas.

A relação entre identidade e alteridade é um componente basilar de qualquer processo de comunicação, porém os modos pelos quais essa relação se constitui são necessariamente históricos. A contemporaneidade e as novas tecnologias possibilitaram meios inéditos para que a atividade verbal e interação social se materializem: aplicativos de relacionamento (Happn, Tinder), conversas individuais e em grupos (Messenger, WhatsApp) edição e envio de conteúdo imagético diverso (Instagram, Snapchat), em meio a outros exemplos possíveis, ilustram variações de formas de materializar a sociabilidade online. No princípio da popularização da Internet para uso doméstico, no final do século XX, a geração e publicação de conteúdo encontravam-se sob o domínio de portais e sites oficiais da imprensa (UOL, Folha de S.Paulo, Veja etc.). Ocorreu, sobretudo no início do século XXI, uma mudança paradigmática que ampliou a quantidade de internautas capazes de publicar enunciados online, especialmente em blogs, redes sociais e páginas gratuitas. Essa nova modalidade da web é denominada como 2.0, em contraste com a antecessora web 1.0, menos dinâmica e colaborativa.

O primeiro autor a cunhar essa web como 2.0 foi DiNucci (1999), ao enfatizar o aspecto interativo dessa nova forma de rede que, até o momento, era apenas um embrião. Golbeck (2013) afirma que um maior grau de interatividade é possível graças à abertura e simplificação de possibilidades para os internautas se tornarem autores dos mais diversos enunciados e, simultaneamente, viabilizar canais responsivos para uma maior parte dos usuários. Dessa maneira, permite-se que mais leitores se posicionem com comentários, contribuições e críticas ao conteúdo publicado. Essa transformação produziu consequências no que Bakhtin (2010a) denomina como inter-relação "euoutro". Nesse contexto, o internauta passa a transitar entre a posição de leitor e autor. Embora em cada ato responsivo se assuma determinada posição, durante a navegação move-se constantemente entre ambas as condições.

De um ponto de vista axiológico, essa ruptura viabilizou aos internautas a expressão mais veloz e dinâmica de um posicionamento ético e ideológico frente aos diversos enunciados que compõem a trama de relações discursivas na Internet. Em um segundo grau, as redes sociais ensejam tanto a publicação de enunciados por seus membros, quanto a criação de possíveis nó ${ }^{2}$ em grupos formados por hobbies e gostos em comum (esporte, música, cinema); compartilhamento de visão de mundo (movimentos sociais, perspectivas políticas) ou por afinidade intrapessoal (amigos de infância, colegas de trabalho) etc.

Nas redes sociais estabelecidas na Internet, a qualidade real dessas interações pode variar em intensidade e propriedades, isto é, tais pessoas podem, ou não, realmente se conhecer offlline, ser extremamente próximas ou, ainda, somente terem contato

\footnotetext{
${ }^{2} \mathrm{Na}$ linguagem dos estudos de redes sociais elaborada por campos das ciências sociais (antropologia, ciência política e sociologia), o conceito de nó é comumente empregado para designar as ligações entre dois "pontos" de uma rede social, isto é, algum grau de relação social engendrada por dois agentes.
} 
superficial. Apesar da gama de diferenciações possíveis de intimidade entre os agentes sociais, essas conexões são comumente qualificadas de forma genérica: "seguidores", "leitores", "fãs" ou "amigos" nas redes sociais online. Uma característica central dos membros dessas redes é, portanto, a possibilidade de relacionar-se responsivamente tanto com o conteúdo publicado pela imprensa e mídia online, quanto com os demais usuários a eles associados.

Outro traço distintivo desse autor/leitor em redes sociais é a sua característica hipertextual. O conceito de hipertexto, embora mais notório nas novas tecnologias, data de meados do século XX. Bush (1945) postulou a criação de uma rede de informações associativa, diferente das ordens numéricas e alfabéticas, como a ordem dos verbetes em um dicionário, ou a disposição de livros na biblioteca. Nelson (1965) foi o primeiro a coroar nominalmente a ideia de hipertexto, sugerindo uma leitura mais "intuitiva" e "nãolinear" estabelecida em dispositivos digitais, ao invés de impressas no papel. Apenas décadas mais tarde, em meados de 1990, diante do crescimento do uso de computadores no uso doméstico e profissional, o conceito de "leitor hipertextual" passou a ser utilizado por autores como Moulthrop (1994), Bolter (1997) e Bloor (1997). Esse leitor de conteúdo digital, portanto, não pode ser considerado similar ao leitor de um gênero do discurso como o romance tradicional, cuja leitura típica se inicia na primeira página e segue, no geral, de modo linear até o seu final.

A dinâmica de uma rede social online propicia um processo contínuo de avaliação das palavras de outrem. Em um post (postagem) ${ }^{3}$ é especialmente incerto qual comentário ou réplica dará o que Bakhtin (2010a) classifica como a "última palavra". Diante de milhões de outros membros, é difícil elaborar o cálculo final de quais serão as reações manifestadas pelas posições axiológicas e ideológicas frente ao conteúdo inicial. A soma da pluralidade cultural e valorativa observada nos usuários do Facebook com a variedade de recursos semióticos disponíveis aos usuários, nessa rede, resulta em um corpus multifacetário e complexo.

Tal panorama expõe um dilema na análise dos enunciados presentes no Facebook. De um lado, há a heterogeneidade das características de uma rede social e, portanto, privilegiar somente uma propriedade dos enunciados analisados é desconsiderar o sincretismo semiótico e a pluralidade dos agentes sociais constituintes da rede. Por outro lado, esmiuçar todas essas nuances no Facebook resultaria na formação de um gigantesco mosaico de fragmentos sem que esta soma de propriedades resulte em uma análise coesa.

A miríade constitutiva das redes sociais é composta, ademais, por sua capacidade de englobar uma série de esferas, sendo possível encontrar páginas de arte, cotidiano, esporte, política, religião etc. Diante da inviabilidade de analisar pormenorizadamente os enunciados produzidos por cada um desses campos no Facebook, optou-se por selecionar páginas de divulgação científica como elemento de estudo. Conforme indicado por Grillo

\footnotetext{
${ }^{3}$ No decorrer do presente artigo, optou-se por adotar a forma em língua inglesa para designar parte das ferramentas disponíveis no Facebook e na Internet. Essa escolha se deve ao fato de que entre os falantes de língua portuguesa o "post" se tornou uma forma comum de se referir a esse tipo de enunciado publicado na rede, de forma similar ao uso de palavras como e-mail, chat e blog. Outro incentivo positivo para optar por "post" é o respeito à forma original empregada pelo próprio Facebook. Deve-se esclarecer que a ação de enviar um "post" é comumente expressa como o ato de "postar", na qual um verbo já dicionarizado em língua portuguesa é reaproveitado com uma nova acepção.
} 
(2013), a divulgação científica se dá como resultado da relação dialógica entre diversas esferas: a educacional, a jornalística e a científica, que submete seus saberes à avaliação crítica de leitores oriundos dos mais diversos campos de atividade humana. Essa característica híbrida da divulgação científica a torna, portanto, uma produção discursiva privilegiada por mobilizar panoramicamente uma rede social.

O presente artigo observa, com maior precisão, a maneira pela qual a responsividade é estabelecida entre os usuários do Facebook e as páginas de revistas de divulgação científica selecionadas para estudo (Pesquisa FAPESP, Scientific American Brasil e Superinteressante). Diante da maior interatividade produzida pela web 2.0, é necessário considerar que a ruptura de linearidade da leitura tradicional é apenas parte das características desse internauta como autor/leitor. Ao considerar que as redes sociais disponibilizam formas responsivas estandardizadas e quantificadas, investiga-se, nesse estudo, parte de suas consequências no âmbito do discurso e da linguagem.

\title{
2 METODOLOGIA E CORPUS
}

\author{
Independentemente de quais sejam os objetivos de uma pesquisa, só o texto pode ser o ponto \\ de partida.
}

(Mikhail M. Bakhtin)

Os conceitos mobilizados pelos autores do Círculo de Bakhtin focalizam uma série de aspectos da criação verbal: arquitetônica, autoria, ideologia, estilo, gênero discursivo, entre outros. Diante da inviabilidade metodológica de analisar minuciosamente todas as dimensões constituintes dos enunciados, a opção pela responsividade como elementochave de análise se deve, sobretudo, a dois motivos: i) o fato de o Facebook viabilizar meios particularmente velozes, simples e acessíveis para que a interação verbal entre seus membros se materialize em comparação com a divulgação científica em forma impressa e ii) a centralidade das formas responsivas na avaliação dos enunciados publicados nessa rede social. Tais contrastes são particularmente observáveis na comparação entre jornais e revistas com as páginas de divulgação científica no Facebook. Em seu formato impresso, disponibilizam-se pequenas seções interativas, como as cartas dos leitores, nas quais uma fração relativamente pequena de mensagens é registrada, já nas redes sociais é possível receber uma quantia muito maior de respostas dos usuários via curtidas/reações, compartilhamentos e comentários.

A estandardização da responsividade no Facebook ocorre de maneira mais aguda no uso de curtidas, por essa razão privilegiou-se a sua observação: é o modo mais automatizado, simples e veloz de reagir a um enunciado publicado. Bakhtin (2012) menciona a historicidade concreta, em circunstância e tempo específicos, como determinante para a apreensão de qualquer conteúdo-sentido de uma ação. De forma análoga, Volóchinov advoga que o exame do "horizonte social" é um ponto de partida de seu método da ciência da linguagem. Com o objetivo de apreender esse entorno, elaborase uma breve cronologia das formas responsivas no Facebook, assim como se busca compreender os possíveis resultados da criação de uma ferramenta que produz "respostas" instantâneas aos enunciados publicados nessa rede. 
O segundo esforço de análise se dedica ao exame empírico do corpus. Conciliamse dados qualitativos e quantitativos com o objetivo de observar quais posts obtiveram a maior quantia de curtidas/reações em cada uma das revistas analisadas, assim como características qualitativas - estilo, tema, composição - desses enunciados.

O corpus total é composto pelas publicações enviadas pelas páginas do Facebook das revistas Scientific American Brasil, Pesquisa FAPESP e Superinteressante. O Facebook é, contemporaneamente, considerado a maior rede social na Internet em termos de usuários ${ }^{4}$, o que fez com que boa parte das instituições ligadas à divulgação científica criasse páginas em busca de ampliar o número de leitores e o alcance do material divulgado. Dentre outras páginas presentes no Facebook, as revistas selecionadas são capazes de fornecer um panorama heterogêneo da divulgação científica: i) a Pesquisa FAPESP é de origem pública e se concentra, no geral, nas atividades de acadêmicos, pesquisadores e cientistas brasileiros; ii) a Scientific American Brasil é a versão brasileira da revista estadunidense homônima e fornece um panorama do campo científico nacional e internacional, frequentemente destacando temas que também foram mencionados na versão norte-americana e iii) a Superinteressante mescla curiosidades científicas, entretenimento e referências ao que Adorno (2002) qualifica como "indústria cultural" (filmes, quadrinhos, música e esporte).

Arquivou-se previamente o conteúdo enviado durante o intervalo de quatro meses de 2016 (1 de março / 30 de junho) das três supramencionadas páginas oficiais das revistas. As páginas selecionadas possuem um perfil editorial variado, cujos elementos repercutem nos posts mais curtidos. A curtida, que é um índice de algum grau de atenção obtido por um enunciado, que pode ser motivado por seu estilo, conteúdo temático, forma composicional, autoria, visualidade etc., guia a análise.

\title{
30 ATO DE CURTIR COMO FORMA RESPONSIVA
}

\begin{abstract}
$\mathrm{Na}$ indústria cultural o indivíduo é ilusório não só pela estandardização das técnicas de produção. Ele só é tolerado à medida que sua identidade sem reservas com o universal permanece fora de contestação. [...] O individual se reduz à capacidade que tem o universal de assinalar o acidental com uma marca tão indelével a ponto de torná-lo de imediato identificável.
\end{abstract}

(Theodor W. Adorno)

A responsividade dos usuários do Facebook se estabelece, sobretudo, por três formas: i) comentários; ii) compartilhamentos e iii) curtidas. Dentre elas, a maneira mais simples e frequentemente utilizada de avaliação responsiva de posts, comentários e páginas é agraciá-los com curtidas. Adorno (2002) assinala que a estandardização tem a capacidade de reduzir o individual à padronização, tornando-o universal e imediatamente identificável. As curtidas e reações produzem a uniformização da multiplicidade responsiva sob o click de um mesmo botão.

\footnotetext{
${ }^{4}$ Até a publicação do presente artigo, o Facebook possuía a média diária de usuários de 1,37 bilhão e mensal de 2,07 bilhões. Fonte: <https://newsroom.fb.com/company-info/> Acesso em 06 dez. 2017.
} 
A curtida é um pequeno prêmio dado ao conteúdo que, de algum modo, o leitor deseja positivar ou, em certos casos, manifestar alguma forma de filiação, interesse e/ou afetividade. Uma quantidade maior de curtidas é, portanto, um indicativo de que algum fator constitutivo do enunciado - visual, verbal ou sonoro - atraiu a atenção de um maior número de leitores ao ponto de eles afirmarem esse apreço perante os demais membros do Facebook.

Para compreender a importância das curtidas, deve-se reconhecer a relevância social dessa ferramenta entre os usuários da rede social, uma vez que os nomes, imagens de perfil e o número de usuários que curtiram são expostos ao lado das páginas, posts e comentários. As curtidas funcionam, portanto, como um sistema de gratificação instantâneo no qual se estabelece um sistema de troca de capital simbólico entre os diversos integrantes do Facebook. O capital simbólico é definido por Bourdieu (1989) como fama, prestígio, reputação, credibilidade etc. Outras formas de capital - cultural, econômico e social - podem ser transmutados para capital simbólico, na medida em que são percebidos e reconhecidos como legítimos. As formas responsivas do Facebook se tornam, portanto, moedas quantificadas e acumuláveis desse tipo de capital entre os seus membros.

Em relação ao símbolo original da curtida, trata-se de uma ilustração do que comumente classifica-se, em língua portuguesa, como o "sinal de positivo". De acordo com Sherzer (1991), é uma das expressões típicas da linguagem corporal no ocidente (Américas e Europa), cuja origem remonta à antiguidade clássica. Popularmente, o sinal de positivo foi historicamente associado ao veredito sobre vida ou morte dos gladiadores nas arenas, embora essa origem ainda necessite ser confirmada. De acordo com outros autores, Morris et al. (1979), é provável que esse gesto seja ainda mais antigo, pois se estabelece pela expressão corporal de forma dicotômica entre o positivo (polegar direcionado para cima) e o negativo (polegar direcionado para baixo).

Figura 1 - 0 "botão" de curtir original do Facebook

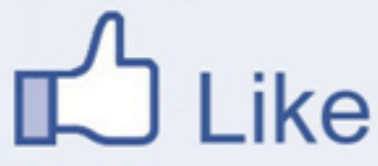

Fonte: <http://www.turquoise-creative.co.uk/facebook-redesigns-like-button>.

Sherzer (1991) afirma que o uso do polegar direcionado para cima é especialmente popular e produtivo no Brasil. Ao contrário de outras nações, esse sinal é utilizado em uma variedade de ocasiões corriqueiras da vida social, quando se deseja positivar determinada ação ou enunciado sem o acompanhamento verbal, assim como para agradecer alguém ou, até mesmo, em determinadas formas de despedida. Os usos do "sinal de positivo" são, portanto, variáveis, sendo mais ou menos frequentes, embora, de forma geral, expressem uma avaliação favorável em relação a algo ou alguém.

No blog oficial do Facebook, Pearlman (2009), co-criadora do botão de curtir, detalhou que uma das motivações para a criação dessa ferramenta foi propiciar um atalho capaz de substituir pequenos enunciados de teor afetivo como "incrível" e "parabéns". A 
simplificação gerada pela criação desse botão vem ao custo de que uma curtida pode ser motivada por uma série de fatores. Diante de um mesmo post, diferentes leitores podem curti-lo em virtude de distintas razões: concordância com o argumento exposto por algum sujeito-autor; interesse por um determinado tema, admiração estética ou ainda apenas devido a uma correspondência ideológica parcial ou total com o enunciado. No limite, a curtida pode ser utilizada até mesmo de maneira irônica, quando empregada como modo de demonstrar uma falsa apreciação por algo para o qual, de fato, não se tem qualquer predileção, concordância ou forma de emoção positiva. A variedade de motivações responsivas são todas conjugadas sob uma mesma expressão sígnica, uma vez que a estandardização as reduz a um aspecto similar e padronizado.

Gradativamente o Facebook passou a viabilizar um número maior de formas preestabelecidas de se posicionar frente a um post. A partir de atualizações feitas durante os anos de 2015 e 2016, ampliou as possibilidades de curtir para diferentes tipos de reações (figura 2): curtir (like), amei (love), haha, uau (wow), triste (sad) e grr (angry). O acréscimo de novas reações certamente adiciona novas nuances para a avaliação de enunciados no Facebook, porém seguem como expressões genéricas e estandardizadas da responsividade, uma vez que são apenas indicativos da impressão geral causada no leitor hipertextual.

Figura 2 - Novas possibilidades de reações a um post no Facebook a partir do botão de curtir

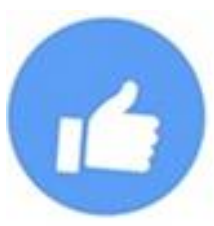

Like

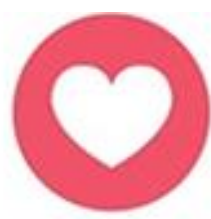

Love

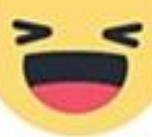

Haha

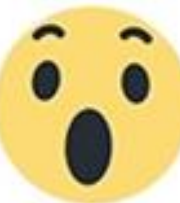

Wow

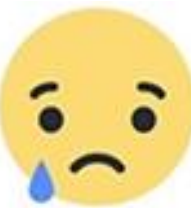

Sad

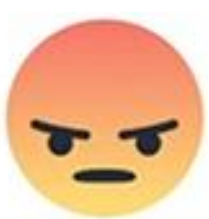

Angry

Fonte: <www.facebook.com>

Durante o dia das mães em 2016 e 2017, o Facebook adicionou temporariamente outra possibilidade de reação para seus usuários; o botão de gratidão (thankful) foi removido das opções de reações após esse período. A inserção de novas reações induzidas por festividades ou pelo interesse de ampliar temporariamente as possibilidades disponíveis aos usuários é, portanto, algo factível, como no mês em que foi celebrado o orgulho gay (figura 3).

Figura 3: Reação de gratidão (thankful) e orgulho (pride)

\section{Thankful Pride}
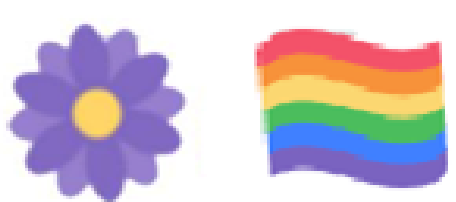

Fonte: <www.facebook.com> (imagem adaptada). 
É necessário considerar que o usuário do Facebook, ao acessar o seu feed de notícias, depara-se com uma série de enunciados com diferentes características linguísticas, axiológicas e semióticas. O leitor hipertextual nesse contexto, de acordo com a média dos resultados obtidos, em todas as páginas analisadas, demonstra ter preferência pelo uso de curtidas como a forma mais popular de expressar alguma reação diante do conteúdo de um post (gráfico 1).

\section{Gráfico 1 - Soma total $(\Sigma)$ de curtidas, compartilhamentos e comentários}

$\square$ Comentários $\square$ Compartilham entos $\mathbf{D}$ Curtidas

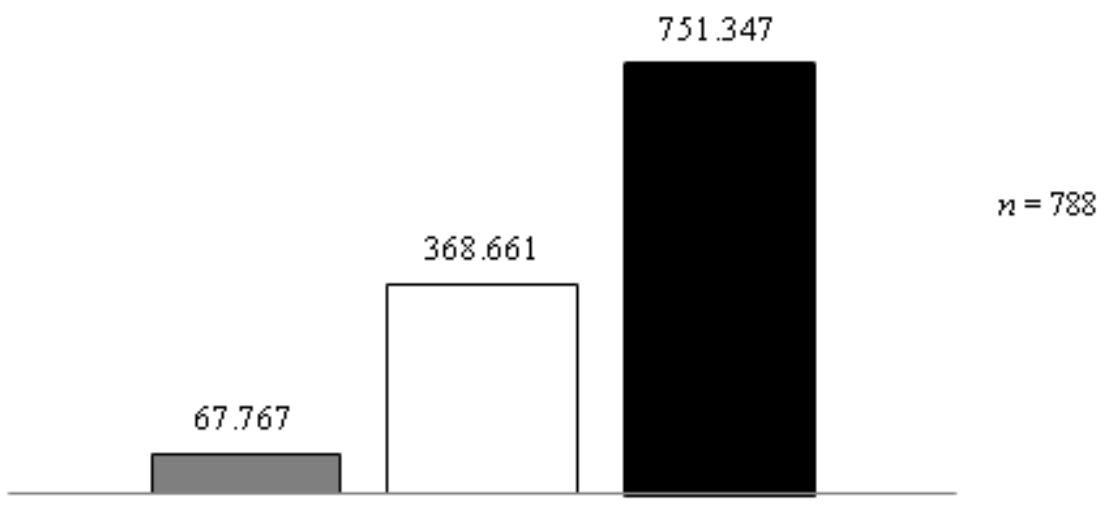

Positivar um post de maneira estandardizada não é uma exclusividade do Facebook. Outras redes sociais online como o Instagram, que a partir de abril de 2012 foi adquirida pela corporação do Facebook, e o Twitter, que substituiu a opção de "favoritar" por "curtir", adotam ferramentas similares. A rede social Google + também possibilita que os usuários positivem um post com um “+1". Ainda que haja variações na forma de denominar tais avaliações favoráveis, a significação de tais gestos é relativamente semelhante, assim como o fato de serem agregados de forma quantitativa, isto é, sempre somar o número de membros da rede que positivaram um dado post, página ou comentário.

Há indícios, portanto, de haver uma tendência geral das maiores redes sociais na Internet em disponibilizar meios estandardizados de responsividade. Particularmente no Facebook, a opção de curtir é tão característica da rede que a corporação detém a patente comercial sobre o ícone com o gesto de polegar direcionado para cima nas cores branca e azul, tal qual é apresentado em suas páginas ${ }^{5}$.

5 Lista completa de patentes comerciais sob o domínio da corporação Faceboook: <https://www.facebookbrand.com/trademarks/>. Acesso em 19 nov. 2017. 


\begin{abstract}
Nenhum reflexo sobre mim mesmo pode me concluir integralmente, pois, sendo imanente à minha consciência responsável e única, torna-se fator de sentido e valor do desenvolvimento ulterior dessa consciência; minha própria palavra sobre mim mesmo não pode ser essencialmente a última palavra.
\end{abstract}

(Mikhail M. Bakhtin)

A quantificação das curtidas opera como um dos índices capaz de sinalizar os posts que mais atraíram a atenção dos leitores expressa pelos meios responsivos. Antes de investigar as características composicionais dos enunciados mais curtidos, examinam-se os dados quantitativos e qualitativos obtidos pela pesquisa. Faz-se necessário, em primeiro lugar, destacar e refletir sobre as disparidades na quantidade total de curtidas recebidas por cada revista no total dos posts publicados durante o período de arquivamento das publicações.

\title{
Gráfico 2 - Somas $(\Sigma)$ de curtidas dos posts arquivados em cada página \\ $\square$ Pesquisa FAPESP (PF) प Scientific Am erican Brasil (SA) D Superinteressante (SI)
}

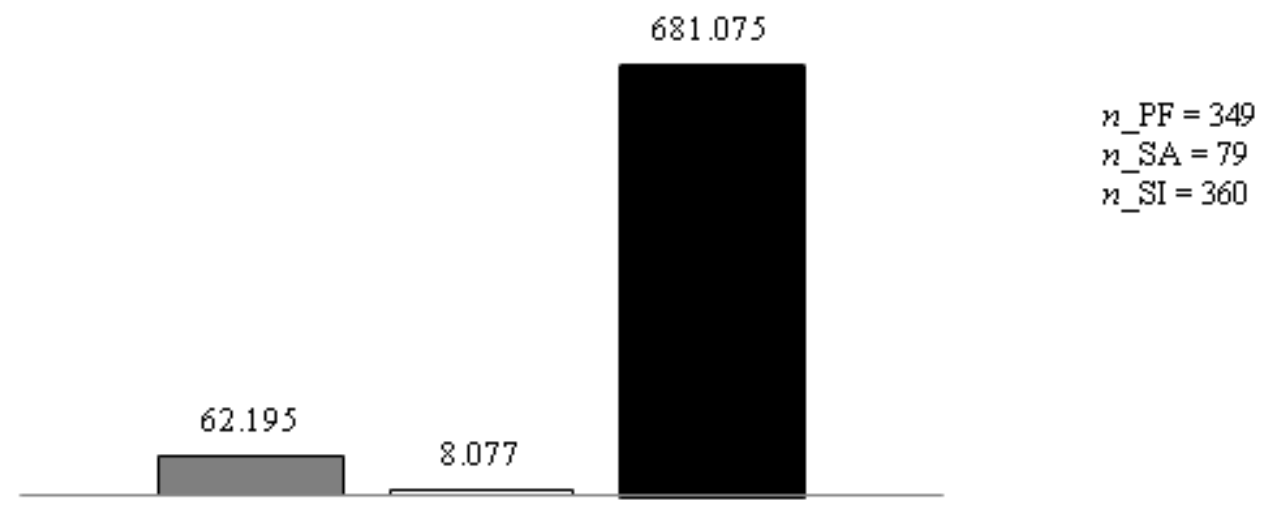

Ao se deparar com os diferentes montantes resultantes de curtidas totais dos posts de cada revista, faz-se inevitável a indagação acerca dos motivos de o total de curtidas recebido pelos posts da página da revista Superinteressante ser diversas vezes maior que o das demais páginas. Os posts da página da revista Superinteressante acumularam maior quantidade de curtidas (681.075) que os posts da Pesquisa FAPESP (62.195) e Scientific American Brasil (8.077). Importa considerar o grau de diferença na comparação, pois o total acumulado pela Superinteressante foi mais de dez vezes maior do que o da segunda revista pesquisada (Pesquisa FAPESP). Um dos pontos de partida dessa análise será compreender os motivos de tal diferença.

Salienta-se que, apesar de haver relevante disparidade estatística, uma série de fatores deve ser considerada antes de tecer qualquer síntese final sobre tal comparação. Um ponto inicial para esclarecer as razões dessa diferença é o número de posts que cada 
uma das revistas publicou durante o dado período. A página da revista Superinteressante foi a que apresentou atividade mais intensa em números absolutos $\left(n \_\right.$SI $\left.=360\right)$ durante o período de quatro meses, resultando em uma frequência de quase três posts por dia $(2,92$ posts). Em tal comparação, a página da revista Pesquisa FAPESP publicou quase a mesma quantidade de posts que a revista Superinteressante $\left(n \_\mathrm{PF}=347\right)$ : em média foram publicados 2,84 posts por dia. A página da revista Scientific American Brasil teve o menor número de atividades na rede $\left(n \_S I=79\right)$, menos de uma vez ao dia na média $(0,61)$. Considerando tais disparidades entre a intensidade de atividades das revistas em suas respectivas páginas no Facebook, verifica-se que o grau de diferença entre o total de curtidas per post das páginas da Pesquisa FAPESP e da Scientific American Brasil diminui acentuadamente. No total acumulado por essas duas páginas, a distância era maior do que sete vezes $(62.195 / 8.077=7,70)$ porém, quando comparada apenas a média de curtidas, a diferença cai para menos que o dobro $\left(\overline{\mathrm{x}}_{-} \mathrm{PF} / \overline{\mathrm{x}}_{-} \mathrm{SI}=1,83\right)$.

\section{Gráfico 3 - Médias $(\bar{x})$ de curtidas por post}

$\square$ Pesquisa FAPESP (PF) $\square$ Scientific Am erican Brasil (SA) $\square$ Superinteressante (SI)

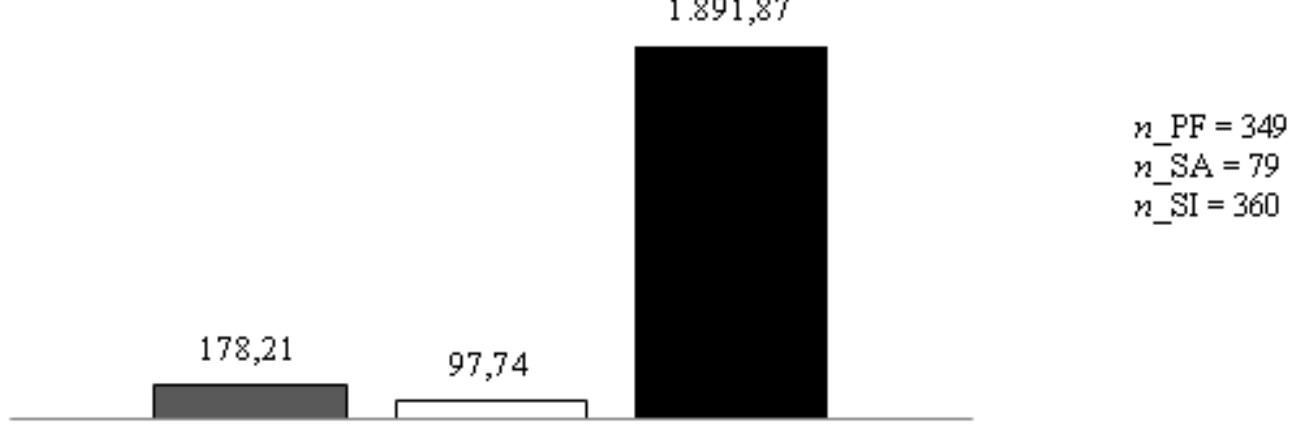

Ao considerar apenas a média de curtidas, os posts da revista Superinteressante seguem apresentando uma média de curtidas muito superior à das demais revistas. Um segundo fator distintivo é o de que essas páginas possuem diferentes quantidades de fãs/seguidores. Consistente com os resultados de outra pesquisa (MALHOTRA; MALHOTRA; SEE, 2013), o número de fãs é uma importante variável para determinar a área de alcance imediata e repercussão para um maior número de pessoas, pois facilita a divulgação dos enunciados postados entre os membros do Facebook que seguem e curtem determinada página.

Uma forma análoga de comparação é possível fazer ao tomar a quantidade de tiragem das revistas em sua forma impressa como índice comparativo, o que explicita uma tendência correlata ao que acontece no Facebook entre as páginas das revistas investigadas. A partir de dados divulgados entre os anos 2015 e 2016, a revista Superinteressante teve tiragem de aproximadamente $354.260^{6}$, a revista Pesquisa

6 Dados divulgados pela Editora Abril em seu site oficial: <http://web.archive.org/web/20150529210350/http://publiabril.abril.com.br/tabelasgerais/revistas/circulacao-geral> Acesso em 11 set. 2016. 
FAPESP teve tiragem de $43.400^{7}$, enquanto a Scientific American Brasil teve a menor delas, com $33.000^{8}$.

Há, portanto, certa correspondência entre a popularidade das revistas na forma impressa e o modo pelo qual ela reverbera em redes sociais na Internet. Ressalta-se que tal padrão se repete em outra rede social, o Twitter $^{9}$, na qual a mesma ordem de popularidade é observada na comparação entre as três páginas oficiais, reforçando os laços que relacionam o poder de divulgação das revistas de forma online e off-line.

É esperado, portanto, que a maior tiragem e distribuição fora da rede facilitem a obtenção dos milhões de fãs da Superinteressante (3.854.770) e possibilite chances maiores de somas absolutas de fãs do que a Pesquisa FAPESP (134.470) e a Scientific American Brasil (131.248).

Esse número elevado de curtidas, apesar de ampliar o raio de divulgação dos posts entre os fãs e torná-los mais suscetíveis a curtir, compartilhar ou comentar publicações feitas pela revista, não garante a intensidade e frequência de responsividade de cada fã isoladamente. O gráfico 4 expressa que o inverso, na verdade, ocorre em relação ao número de fãs necessários para cada curtida em um post de cada página, especialmente na página da Superinteressante.

\section{Gráfico 4 - Relação entre total de seguidores da página por curtida em um post}

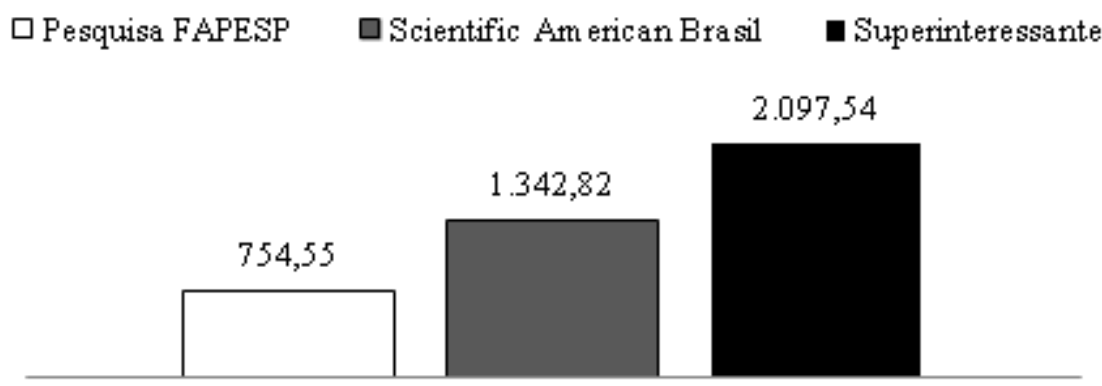

O gráfico acima indica que para cada 2.003,41 usuários que curtem a página da revista Superinteressante, apenas um resultará em uma curtida para cada post. Sendo assim, apesar de ter um total muito maior de seguidores, eles são quantitativamente menos ativos que os da Pesquisa FAPESP e da Scientific American Brasil. Nessa comparação, é preciso fazer uma série de comentários e interpretações dos dados apresentados: i) não é provável que os fãs das páginas sejam os únicos a curtir os posts publicados por ela, pois todas as páginas analisadas não exigem a obrigatoriedade de se tornar um fã para curtir

\footnotetext{
7 Dados divulgados pela Associação Nacional de Editores de Publicações em seu site oficial: $<$ http://www.anatec.org.br/index.php/component/content/article/30-midia-impressa/ciencia-educacao-elinguistica/88-pesquisa-fapesp> Acesso em 11 set. 2016.

8 Dados divulgados pela Associação Nacional de Editores de Publicações em seu site oficial: <http://www.anatec.org.br/index.php/component/content/article/30-midia-impressa/ciencia-educacao-elinguistica/652-scientific-american-brasil> Acesso em 11 set. 2016.

${ }^{9}$ Comparação extraída de dados das páginas oficiais das revistas <https://twitter.com/pesquisafapesp $>$ (30.600 de fãs/seguidores) <https://twitter.com/sciambrasil> (5.898 de fãs/seguidores) e $<$ https://twitter.com/revistasuper> (2.960.000 de fãs/seguidores) Acesso em 09 out. 2016.
} 
os posts da página ${ }^{10}$; ii) o número total de curtidas das páginas da Pesquisa FAPESP e Scientific American Brasil são relativamente semelhantes, mas a Pesquisa FAPESP necessita de menos fãs para cada curtida recebida por post; um fator que pode haver contribuído para o maior engajamento de seus fãs nos posts é que a Pesquisa FAPESP tenha se demonstrado mais ativa nos meses estudados, tendo publicado posts com maior frequência que a Scientific American Brasil e, assim, consolidando fãs quantitativamente mais constantes na sua responsividade; iii) uma hipótese capaz de explicar o menor engajamento quantitativo em curtidas, levando em conta a relação entre fãs e posts, é que a página da revista Superinteressante tenha seguidores que não sigam com tanto afinco quanto os das demais páginas investigadas, uma vez que a escala de fãs da revista é milionária. Por essa razão, é factível a possibilidade de ter atraído um público mais amplo, porém interessado em menor grau no conteúdo divulgado pela página.

Ao considerar médias absolutas e tendências gerais, como os resultados expostos nos últimos quadros organizados, inevitavelmente se perdem detalhes de variações internas dentro do material analisado, decorrentes de uma série de fatores melhor analisados de modo qualitativo. Para encerrar a análise quantitativa das curtidas em cada uma das páginas, demonstram-se as variações internas entre cada uma dessas revistas, exemplificando a magnitude de tais oscilações não apenas entre as páginas, como entre os posts de uma mesma revista.

\section{Gráfico 5 - Mínimo, média e máximo de curtidas por post}

口Mínim o de curtidas(min.) aMédia de curtidas(x) Dáximo de curtidas(max.)

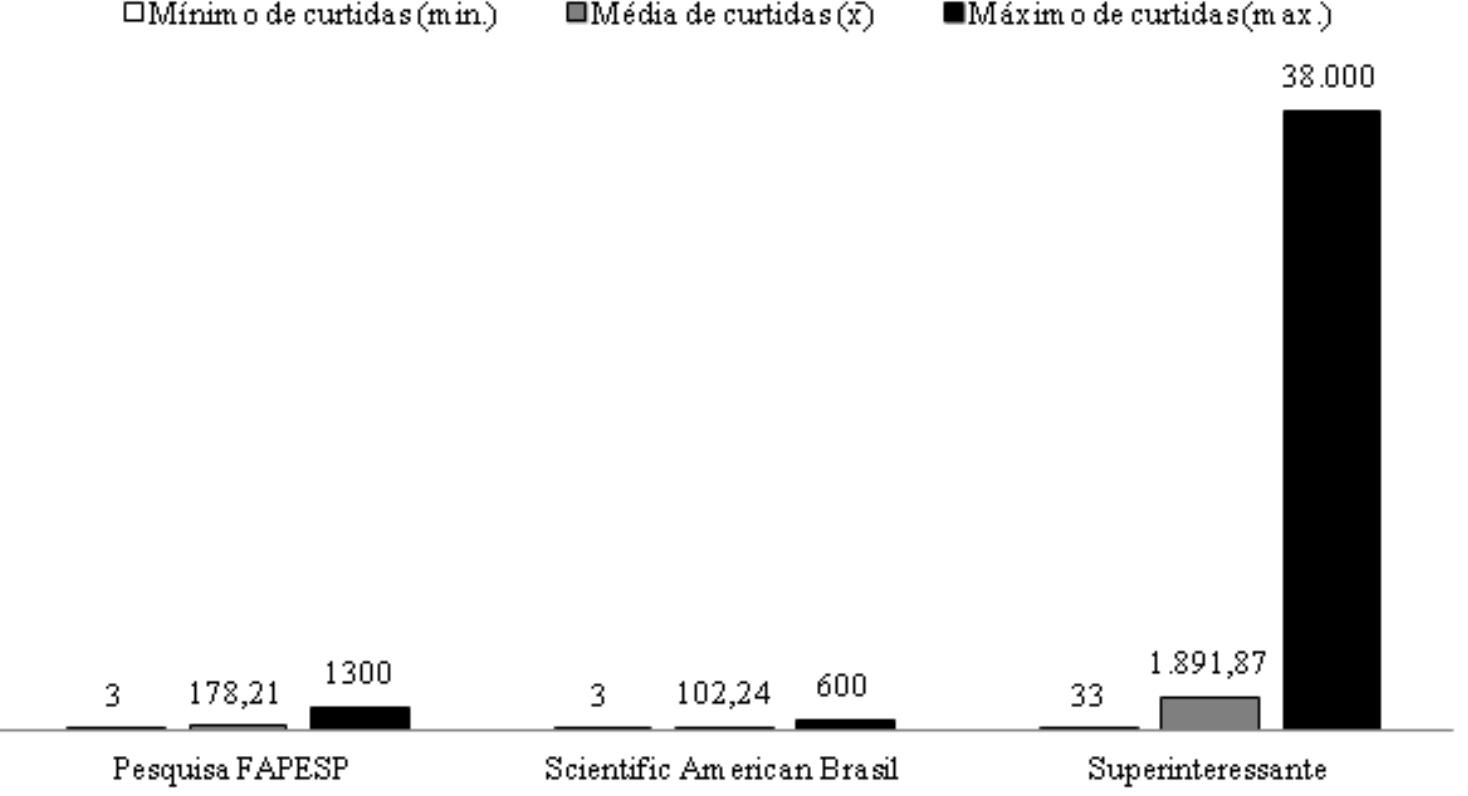

Os resultados expostos acima demonstram a grande variação que há entre o número mínimo, médio e máximo de curtidas por post das páginas de cada uma das revistas. Ressalta-se que, na comparação entre elas, a revista Superinteressante publicou um post

${ }^{10}$ O Facebook possui uma série de variações de privacidade; uma dessas opções possibilita que curtidas, compartilhamentos e comentários sejam restritos apenas aos fãs de uma página, ou aos seus amigos, ou amigos de amigos em páginas pessoais. 
com mais de 38 mil curtidas e, mesmo considerando a quantia média de curtidas por post $\left(\overline{\mathrm{x}} \_\mathrm{SI}=1.924,10\right)$, esse é um número superior aos que mais obtiveram curtidas da página da Pesquisa FAPESP (max._PF = 1300) e Scientific American Brasil (max._SA = 600). Também na comparação interna entre as três medidas de uma mesma página há significativas variações. O que recebeu o mínimo de curtidas da Superinteressante (min._SI $=33$ ) coletou mais de mil vezes menos curtidas que o post mais popular (max._SI / max._SI = 1151,51).

Diante de tais discrepâncias quantitativas, deve-se passar para a análise qualitativa dos posts que resultaram nos maiores índices de responsividade entre os leitores. Analisase, em primeiro lugar, a publicação que obteve mais curtidas entre as da Pesquisa FAPESP (figura 4). Trata-se de uma homenagem às mulheres enviada no dia 8 de março de 2016 - dia Internacional da Mulher. Como a hashtag ao final do enunciado indica (\#DiaInternacionalDaMulher), a data é provavelmente um dos motivos pelos quais esse post tenha se destacado em relação aos demais. Ao clicar no hipertexto da hashtag, é possível acessar outros posts enviados por usuários e páginas que a utilizaram. Sendo assim, além de haver uma sinergia entre o tema e a efeméride, a popularidade da hashtag pode ter viabilizado o acesso de um maior número de leitores e, consequentemente, um maior número de curtidas.

Uma das características particulares desse post (figura 4), na comparação com os demais analisados, é o modo pelo qual ele foi capaz de condensar uma série de gêneros a partir de abertura do hipertexto. Ao acessá-lo, há a exposição de um dossiê com uma série de artigos, entrevistas e reportagens sobre o papel das mulheres na ciência e na academia, assim como os resultados de suas pesquisas e detalhes a respeito das contribuições de pesquisadoras para diversos campos de estudo.

Como forma de destacar a relevância da participação das mulheres nos campos acadêmico e científico, as publicações listadas enfatizam temas relacionados à superação exitosa de barreiras enfrentadas pelas mulheres em profissões predominantemente masculinas. Salienta-se o sucesso auferido por prêmios recebidos por pesquisadoras, assim como a luta contra estereótipos sexistas, especialmente em áreas de pesquisa como a engenharia, nas quais as chances das mulheres em posições de prestígio dentro da área são comparativamente mais escassas. Ademais, são igualmente hipertextualizadas entrevistas com pesquisadoras de diversas áreas (psicologia social, química, educação, pediatria etc.). Em relação a tal publicação, a abertura do hipertexto também agrega variantes semióticas visuais e sonoras, materializadas em vídeos e um podcast ${ }^{11}$ dedicados ao debate sobre as chances de mulheres no ambiente acadêmico-científico. A lista completa com todo o conteúdo acima indicado pode ser acessada a partir do post inicial publicado na página da Pesquisa FAPESP no Facebook.

\footnotetext{
${ }^{11}$ Arquivos de som semelhantes aos programas de rádio, porém divulgados na Internet em plataformas e aplicativos como iTunes, Spotify, Soundcloud, ou diretamente em sites.
} 


\section{Figura 4 - Post com maior quantidade de curtidas da Pesquisa FAPESP durante o período arquivado $^{12}$}

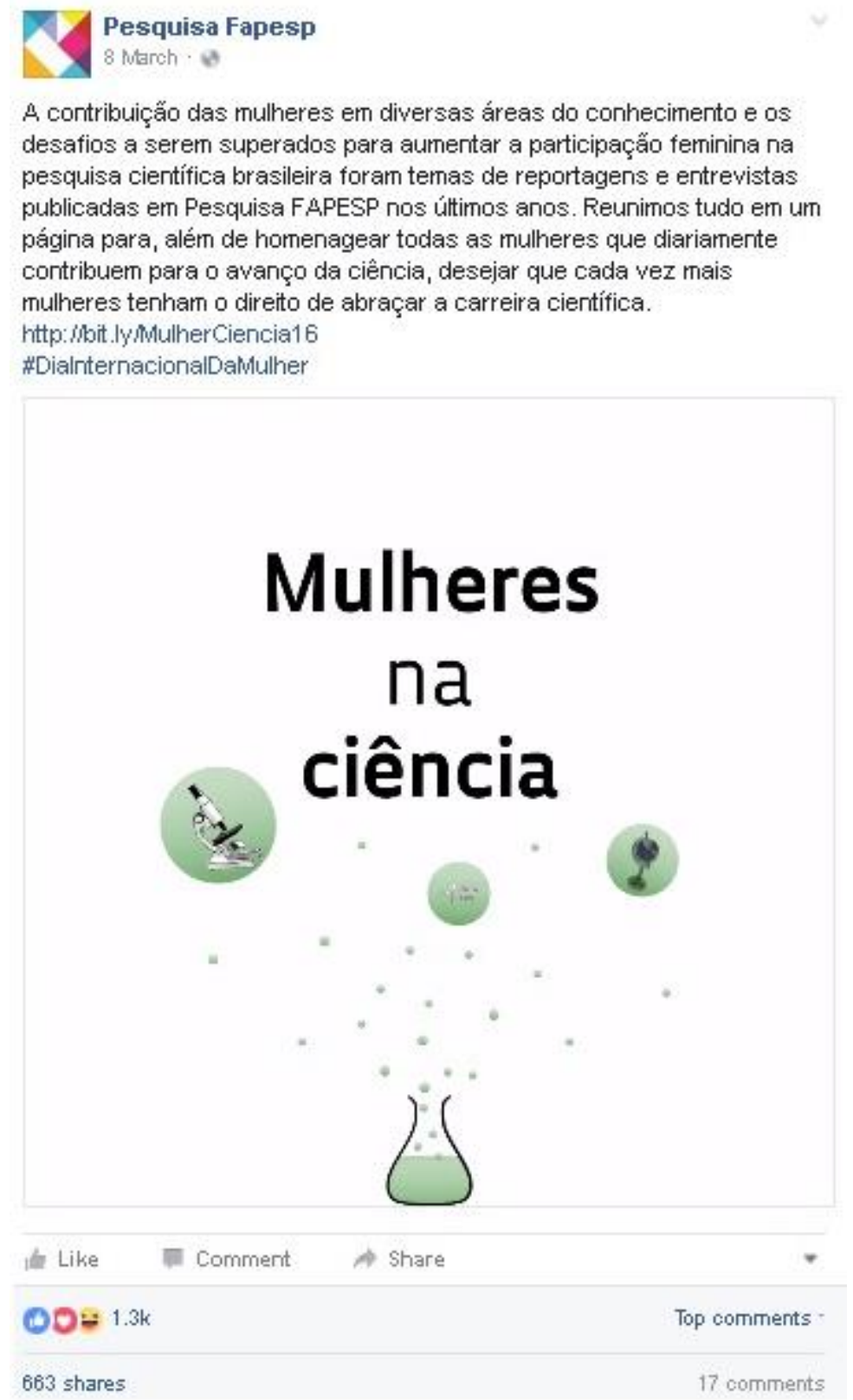

Fonte: https://www.facebook.com/PesquisaFapesp/

Dessa forma, entre artigos, reportagens, vídeos e podcast, detecta-se uma significativa diversidade de gêneros e semioses mobilizados para a composição de uma única publicação no Facebook. A partir do post de homenagem às mulheres, ao considerar apenas os hipertextos tematizados pelas relações entre o gênero sexual feminino e a

12 Durante o presente artigo, os nomes, imagens e conteúdos enviados pelas páginas e leitores foram reproduzidos de forma similar ao publicado originalmente no Facebook. Vale-se da prerrogativa estabelecida nos termos de uso do Facebook para compartilhar todo esse conteúdo: "What's public information? [...] Information you share publicly: When you choose to share something with Public (ex: when you select Public from the audience selector), it's considered public information" Acesso aos termos completos em: < https://www.facebook.com/help/203805466323736 $\geq$ (04 ago. 2017). 
ciência, há setenta e dois hipertextos publicados. Sendo assim, a homenagem às mulheres se consolida como uma forma de republicar diversas publicações anteriormente elaboradas pela Pesquisa FAPESP durante os últimos anos em seu site oficial, ao mesmo tempo que adota um posicionamento axiológico em prol da superação dos desafios sociais enfrentados por mulheres nesse campo, enfatizando as contribuições de pesquisadoras e cientistas mulheres.

Estabelecem-se dois polos a partir de tal post, conforme a proposição engendrada por Bakhtin (2010a): em um polo está a marca do posicionamento autoral e única, favorável à ascensão de mais mulheres em carreiras acadêmico-científicas; no outro polo, há a complexa e heterogênea alteridade que circunda o texto, isto é, tudo aquilo que não é dado dentro do próprio texto. Nesse último polo, é preciso considerar que, ao longo de décadas, esse tem sido um tema estudado por diversas autoras - Rapkiewicz (1998), Citeli (2000), Arrazola (2002), Cabral e Bazzo (2005), Minella (2013), entre outras - que investigaram os desafios de inserção das mulheres no ambiente acadêmico, científico e tecnológico. A persistência de tais estudos ao longo da virada do século demonstra que esse ainda é um desafio a ser superado na contemporaneidade. Além do ensejo propiciado pela efeméride, os desafios profissionais enfrentados por mulheres de outros campos são capazes de endereçar o tema do post para um público mais amplo.

De forma mais panorâmica, o papel das mulheres no mercado de trabalho é um tema que diz respeito, de maneira direta, a aproximadamente metade da população. Esse pode ser um grande incentivo para que parte dos leitores esteja mais propensa a positivar o post, em virtude de apoio ideológico pela igualdade de gênero e por condições semelhantes de ascensão profissional. A divisão sexual do trabalho é um tema capaz de envolver todos os leitores, o que pode gerar simpatizantes da causa também oriundos do sexo masculino.

Na seção anterior mencionaram-se as limitações da opção de curtir no Facebook. Embora haja opções capazes de declarar sentimentos como tristeza e irritação, a expressão de posicionamentos mais claros e complexos perante o conteúdo postado é mais precisamente comunicada na seção de comentários. Na figura 5 há um exemplo de um posicionamento axiológico superior aos limites expressivos das curtidas e reações.

\section{Figura 5 - Comentários no post sobre as mulheres nos campos acadêmico e científico, com maior quantidade de curtidas da Pesquisa FAPESP durante o período arquivado}

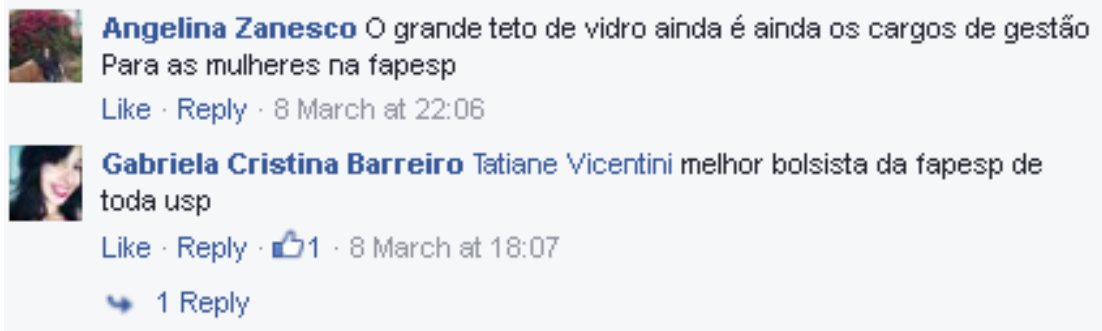

Fonte: <https://www.facebook.com/PesquisaFapesp/>. 
A despeito da popularidade quantitativamente auferida a um post, críticas podem surgir, especialmente na seção de comentários. No exemplo acima (figura 5), Angelina Zanesco questiona a FAPESP sobre a falta de mulheres em cargo de gestão na fundação: "O grande teto de vidro ainda é ainda os cargos de gestão Para as mulheres na fapesp" 13 . O segundo comentário publicado por Gabriela Cristina Barreiro, por outro lado, foi endereçado a uma bolsista da FAPESP e estudante da Universidade de São Paulo (USP), sendo uma forma de homenagear a pessoa marcada no comentário, "Tatiane Vicentini melhor bolsista da fapesp de toda usp".

Bumgarner (2007) reflete que o uso do Facebook tem razões sociais diversas. A princípio, os vínculos afetivos são vitais para a consolidação de uma rede de amigos, mas há também formas mistas de uso: o cotidiano, ideológico, interpessoal, político etc. A diversidade dos conteúdos postados repercute também em diferentes motivações (afetiva, ética, temática) para reagir a um determinado comentário, página ou post.

Ao contrário do post mais curtido da Pesquisa FAPESP, o post mais curtido na página da revista Scientific American Brasil durante o período analisado apresenta composição temática mais específica (física de partículas), sem estar correlacionado com nenhuma efeméride específica (figura 6).

\section{Figura 6: Post com maior quantidade de curtidas da Scientific American Brasil durante 0 período arquivado - sobre os detectores do CERN e os indícios de existência de uma "nova" partícula.}

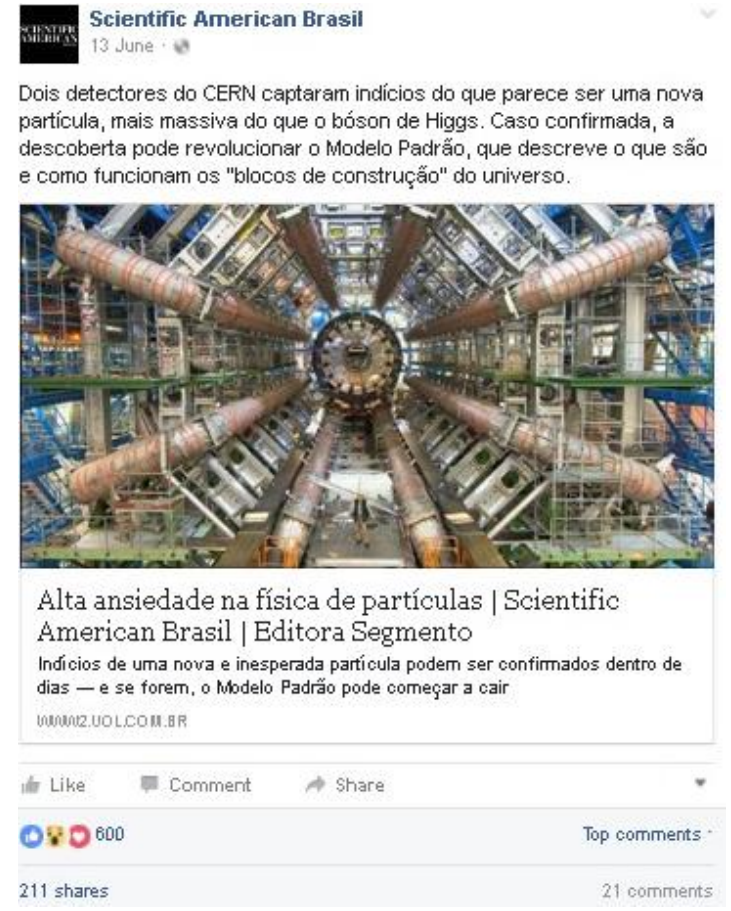

Fonte: <https://www.facebook.com/sciambrasil/?ref=br_rs >.

\footnotetext{
${ }^{13}$ Com o objetivo de manter a originalidade dos enunciados enviados via comentários e a fidúcia aos enunciados enviados pelos leitores que comentaram nos posts selecionados, doravante serão mantidas, tal qual publicadas, todas as variações escritas sem mudanças para a norma padrão da língua portuguesa.
} 
O enunciado verbal menciona o possível surgimento de uma nova partícula que seria mais massiva que o bóson de Higgs, "Dois detectores do CERN captaram indícios do que parece ser uma nova partícula, mais massiva do que o bóson de Higgs". É possível que a atenção gerada pelo conteúdo do post seja derivada de um interesse prévio dos leitores sobre o bóson de Higgs.

Trata-se de uma partícula elementar estudada no campo da física de partículas. Além do nome científico proveniente do sobrenome de Peter Higgs, um dos seis físicos que inicialmente propôs a existência de tal partícula, ela se notabilizou por um segundo nome de "partícula de Deus" (God Particle) alcunhado por Lederman e Teresi (2006). Uma das motivações dos autores, entretanto, era a de enfatizar as dificuldades enfrentadas pela pesquisa relacionada à partícula. Ao invés de criar o nome por qualquer qualidade divina da partícula, os autores afirmam que seria mais apropriado denominá-la em língua inglesa como "Goddam Particle", isto é, uma interjeição mais próxima aos problemas impostos para atingir resultados na pesquisa do que algo relacionado diretamente a uma divindade transcendental. Entretanto, segundo Lederman (2006), o título mais informal não seria aceito pelo editor do livro (p.22), tendo sido, portanto, denominada e, consequentemente, popularizada para o público geral como a "partícula de Deus".

Ainda assim, a proposta feita por Lederman e Teresi (2006), de fato, tece ligações entre o Bóson de Higgs com uma teoria cosmogônica, mais precisamente com a teoria do Big Bang, uma vez que tal partícula tem sido associada às condições iniciais que propiciaram a geração do Big Bang (BERZUKOV; GORBUNOV; SHAPOSHNIKOV, 2009). O enunciado afirma que tais partículas "mais massivas do que o bóson de Higgs" podem, caso sua existência seja confirmada, auxiliar na compreensão de como funcionam os "blocos de construção do universo", possibilidade que pode ter atraído ainda mais leitores a curtir o post.

Apesar de serem apenas ramos de um campo de estudo maior, áreas da física quântica e de partículas se dedicam a elucidar a viabilidade de teorias como a das cordas e a do Big Bang. Tais teorias versam sobre perguntas que inquietam não apenas os especialistas, como também toda a humanidade; respostas para esses mistérios têm sido formuladas ao longo dos séculos desde as narrativas antigas como a Teogonia de Hesíodo e a Bíblia, entre inúmeras outras. Ao longo das últimas décadas, uma série de autores, entre eles, Capra (1975), Chopra (1989) e Goswami (1993) têm utilizado conceitos da física para fundamentar questões relacionadas à religião e à consciência humana, tal uso é criticado por autores como Stenger (1997) que polemiza abertamente com tais autores, classificando-os depreciativamente ora como "misticismo quântico", ora como "charlatanismo quântico".

De qualquer modo, não obstante as polêmicas relacionadas à física de partículas e quântica, esse campo de estudo se popularizou entre os leitores de divulgação científica. O próprio Lederman foi agraciado com diversos prêmios por sua pesquisa, entre eles o Nobel, fator que repercute dentro e fora do campo científico. Um indicativo dessa notoriedade geral é o fato de ter sido o post mais curtido entre o material analisado oriundo da página da Scientific American Brasil. Na seção de comentários são identificados diferentes tipos de leitores que curtiram o post. Parte deles indica leitores que minimamente leram o conteúdo do post e têm conhecimentos prévios sobre a área $\mathrm{e}$ apresentaram críticas qualificadas ao conteúdo, enquanto outros leitores adotaram um maior grau de informalidade nos comentários (figura 7). 
Figura 7 - Comentários no post com maior quantidade de curtidas da Scientific American Brasil durante o período arquivado sobre os detectores do CERN e os indícios de existência de uma "nova" partícula

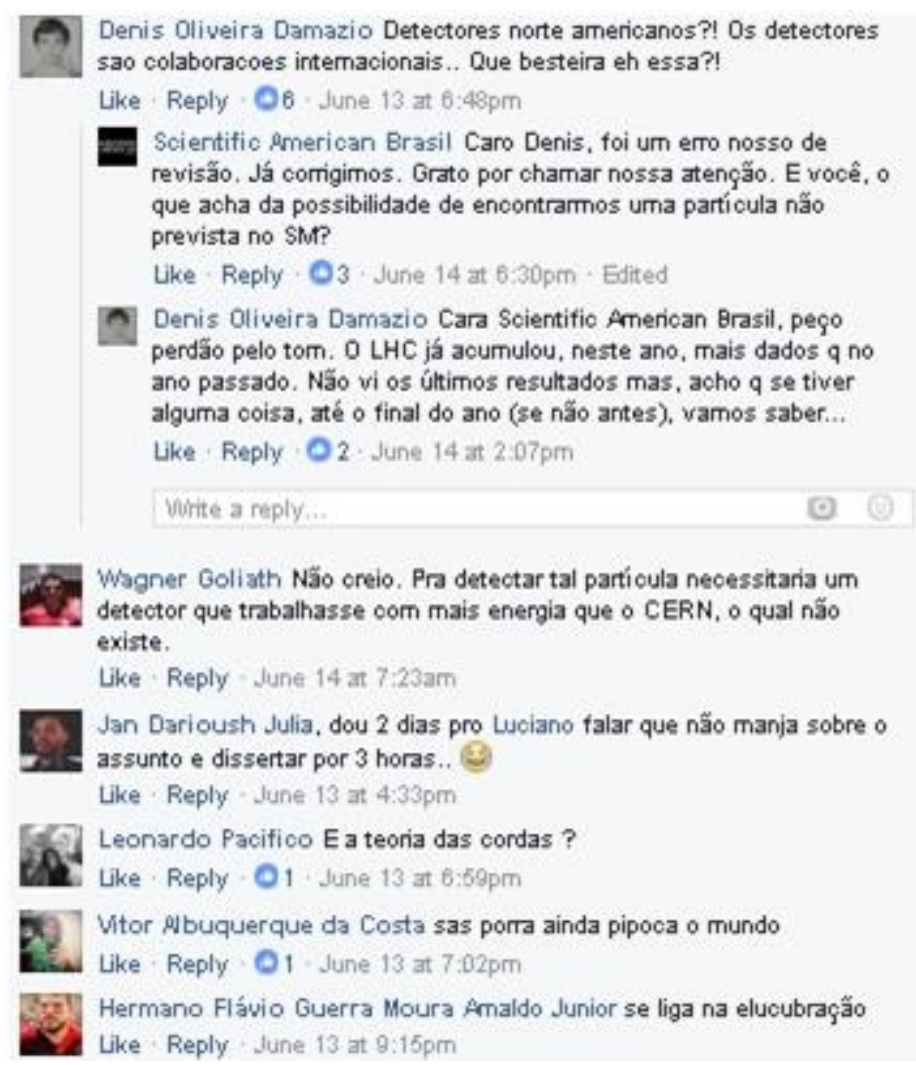

Fonte: https://www.facebook.com/sciambrasil/?ref=br_rs

Denis Oliveira Damazio questiona parte do conteúdo da informação postada, "Detectores norte americanos?! Os detectores sao colaboracoes internacionais... Que besteira eh essa?!". O comentário original foi replicado pela própria Scientific American Brasil, que esclarece ter ocorrido um erro de revisão e agradece a Denis Oliveira Damazio por alertá-los, “Caro Denis, foi um erro nosso de revisão. Já corrigimos. Grato por chamar nossa atenção. E você, o que acha da possibilidade de encontrarmos uma partícula no $\mathrm{SM}^{14}$ ?". Em seguida, Denis envia uma nova réplica ao seu próprio comentário, respondendo a pergunta feita pela Scientific American Brasil. Wagner Goliath também intervém em relação ao estudo da partícula ao comentar, "Não creio. Pra detectar tal partícula necessitaria um detector que trabalhasse com mais energia que o CERN, o qual não existe".

A dinâmica dos comentários é relativamente imprevisível e, na maior parte das vezes, os comentários feitos pelos leitores não são replicados pela própria página da revista. Por outro lado, um post pode ser um ensejo para que mais usuários interajam verbalmente. Como Bakhtin (2010c) afirma, as atitudes responsivas são diversas e se respondem mutuamente de forma a não se posicionar apenas sobre o objeto em questão

\footnotetext{
${ }^{14}$ SM sigla em contração, em língua inglesa, para o Standard Model da área de física de partículas. Em português, é denominado como Modelo Padrão no qual são descritas duas partículas fundamentais: férmions e bósons.
} 
(a possibilidade de uma nova partícula), mas responder ao enunciado alheio (p. 298). Um dos demais comentários demonstra um perfil de leitor interessado no tema e capaz de relacioná-lo com outras questões afins com a área de estudo. Leonardo Pacífico, por exemplo, comenta, "E a teoria das cordas?". Por fim, há ainda comentários mais informais como o feito por Hermano Flávio Guerra Moura "Arnaldo Moura se liga na elucubração" e o de Vitor Albuquerque da Costa, "sas porra ainda pipoca o mundo". Os últimos comentários, em especial, aproximam-se de forma mais acentuada daquilo que Volóchinov $(2009,2017)$ classifica como ideologia do cotidiano. Esses leitores reagem com comentários marcados pela informalidade linguística para questionar sobre os possíveis resultados adversos capazes de colocar o mundo em perigo. Identifica-se, portanto, que a popularidade de um tema pode atrair a atenção de variados tipos de leitores e de interesses.

Figura 8 - Post com maior quantidade de curtidas da Revista Superinteressante durante o período arquivado sobre a faca do faraó Tutancâmon com parte dos comentários dirigidos à publicação

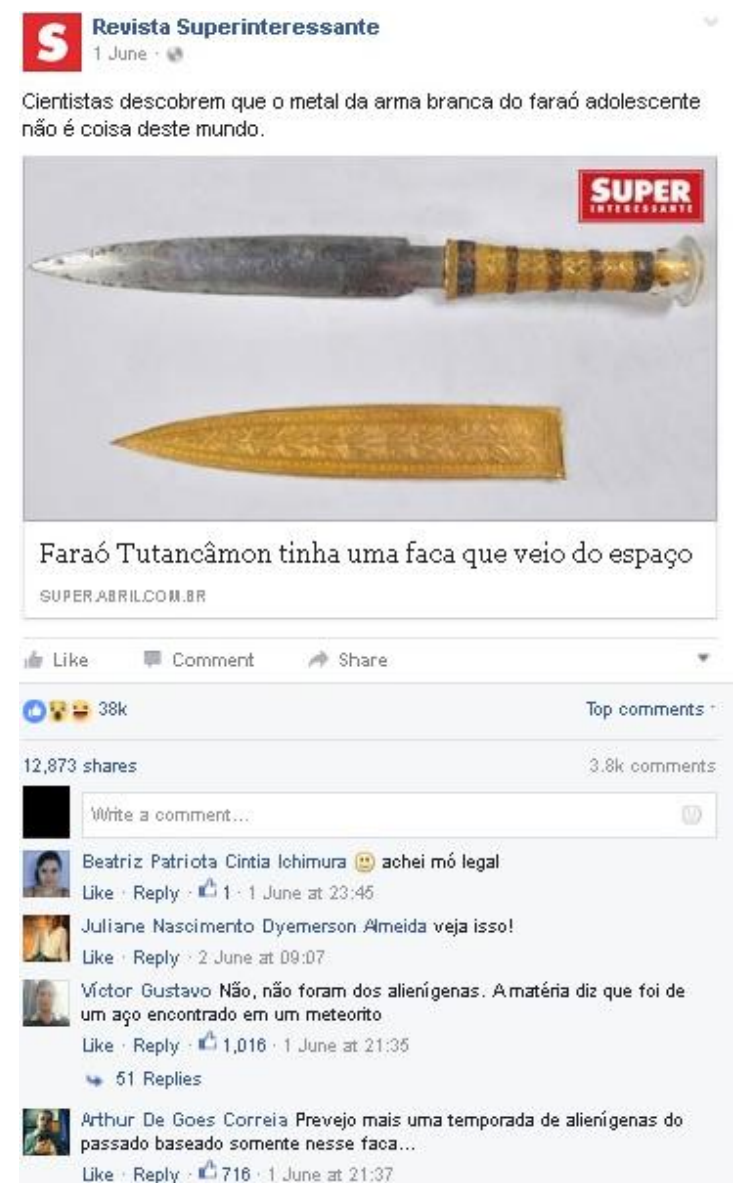

Fonte: <https://www.facebook.com/Superinteressante/>.

Uma característica frequente dos posts mais curtidos é a criação de mistérios, componente também identificado na publicação da Superinteressante, que obteve a maior quantidade de curtidas entre todo o material coletado para a formação do corpus de análise. Apesar de os posts mais curtidos partirem de setores acadêmico-científicos 
distantes, história antiga em oposição à física de partículas, há elementos forjados para capturar a atenção do leitor, "uma partícula mais massiva que o bóson de Higgs" e "Cientistas descobrem que o metal da arma branca do faraó adolescente não é coisa deste mundo".

Os posts capazes de gerar a curiosidade dos leitores e materializar tal atenção inicial em curtidas, mais do que serem compostos por temas populares, possuem resultados e elementos inesperados ("como funcionam os "blocos de construção" do universo"; "Faraó Tutancâmon tinha uma faca que veio do espaço"). Tal ruptura da expectativa média é enunciada de forma a ser verossímil e embasada no argumento de autoridade científica ("Dois detectores do CERN captaram indícios" e "cientistas descobrem"). Como Heath e Heath (2007) afirmam, o inesperado e a credibilidade são dois dos elementos mais potentes para gerar histórias e narrativas capazes de capturar a atenção do público.

Duas das diferenças entre o enunciado do post mais curtido na página da Superinteressante na comparação com os demais são a sua brevidade e, em certa medida, a informação contraditória publicada como manchete. Esse é um exemplo de um fenômeno recorrente na Internet denominado em língua inglesa como click bait (isca de click). De acordo com Blom e Hansen (2015), as manchetes são muitas vezes constituídas por enunciados obscuros e, em diversas ocasiões, são criadas narrativas arquitetadas para ludibriar o leitor e levá-lo a acessar o hipertexto que o leva até a notícia publicada no site oficial. O excerto "Faraó Tutancâmon tinha uma faca que veio do espaço" exemplifica um dos efeitos colaterais possíveis do uso de tais iscas para capturar a atenção do leitor, pois se pode presumir, a partir de tal enunciado, que a faca de Tutancâmon já havia sido confeccionada no espaço ou que, no Egito Antigo, havia uma espécie de relação entre Tutancâmon e seres de outros planetas, como algumas crenças populares professam.

Um dos efeitos adversos do uso de tais iscas é o de que o leitor hipertextual do Facebook pode, por diversas vezes, adotar como estratégia a leitura apenas da manchete e prosseguir para a leitura de um próximo post sem acessar a matéria na íntegra e saber mais detalhes necessários para compreender a notícia satisfatoriamente. $\mathrm{O}$ comentário enviado por Víctor Gustavo, entretanto, esclarece essa falsa interpretação, elucidando que a real origem da faca de Tutancâmon, segundo a matéria, não é proveniente do contato entre o faraó e os alienígenas, mas de um aço oriundo de um meteorito.

Em síntese, a miscelânea temática aparentemente tão diversa na divulgação científica provoca mais curtidas e reações dos leitores quando repercutem em narrativas, problemas e mistérios que historicamente têm inquietado a humanidade: a formação do universo, a forma como nossa sociedade organiza sexualmente o trabalho e enigmas de civilizações antigas. Os exemplos extraídos do corpus de análise revelam um sistema de trocas entre os leitores hipertextuais e as páginas de divulgação científica no Facebook. As formas responsivas presentes nessa rede, sobretudo as curtidas/reações, são interpretadas como capital simbólico. Enquanto as revistas contribuem com conteúdo e saberes, os leitores retribuem com sua própria atenção registrada nas formas responsivas disponibilizadas nessa rede social. 
Os posts mais curtidos de cada página foram um primeiro passo para compreender parte das características dos enunciados que captam maiores índices de atenção entre os leitores. Outros passos possíveis para compreender as novas nuances da responsividade nas páginas no Facebook é analisar com maior profundidade os comentários e os compartilhamentos e suas especificidades em comparação ao uso das curtidas. A presente análise apresenta indícios prévios de que as outras duas formas responsivas são menos padronizadas, embora os detalhes de suas especificidades só possam ser revelados com uma pesquisa de maior fôlego.

A simplicidade das curtidas é um fator que pode explicar por que ela é a forma responsiva mais utilizada pelos usuários do Facebook, na comparação com compartilhamentos e comentários. O benefício da simplicidade, entretanto, vem à custa de ser uma forma estandardizada de se posicionar responsivamente frente a um enunciado. Em outras palavras, as curtidas e reações apresentam claros limites expressivos em comparação com as outras duas formas responsivas (compartilhamentos e comentários).

De forma comparada às revistas impressas de divulgação científica, há nuances que possibilitam estabelecer algumas particularidades importantes dos posts de tais revistas no Facebook. A aquisição massiva de um determinado número de revista opera como um índice de interesse no tema da capa e/ou nos demais conteúdos anunciados. Ao longo do tempo, níveis crescentes de aquisição e assinatura da revista podem ser interpretados como uma forma de adesão discursiva ou de interesse por sua temática frequente. Os posts, entretanto, são capazes de demonstrar uma relação mais direta do interesse ou curiosidade dos leitores a um tema especificamente. Enquanto a revista condensa simultaneamente uma série de gêneros, temas e imagens, os posts do Facebook tendem a isolar tais variáveis discursivas.

É preciso considerar e destacar o caráter parcial dos resultados apresentados diante da magnitude quantitativa de uma rede social com bilhões de usuários, pois apenas com os dados de três páginas não é possível tecer uma conclusão sobre o uso das curtidas como forma responsiva. Outra ressalva é a inviabilidade de extrapolar diretamente tais resultados obtidos para páginas que se valem de outros temas (humor, jornalismo político, esportes).

Deve-se enfatizar, todavia, que os resultados obtidos no presente estudo garantem uma melhor compreensão do comportamento responsivo dos leitores de páginas de revistas de divulgação científica. A possibilidade de vinculá-los com outras páginas e redes sociais como o Instagram, Snapchat e Twitter depende de futuras pesquisas na área que busquem revelar as especificidades de cada uma delas. 
ADORNO, T . W. Indústria cultural e sociedade. Sao Paulo: Paz e Terra, 2002.

ARRAZOLA, L. S. D. Ciência e crítica feminista. In: COSTA, A. A.; SARDENBERG, C. (Org.) Feminismo, ciência e tecnologia. Salvador: REDOR/NEIM/UFBA, 2002. p. 67-76.

BAKHTIN, M. M. Metodologia das ciências humanas. In:___. Estética da criação verbal. Trad. Paulo Bezerra. 4. ed. São Paulo: Martins Fontes, 2003. p. 393-410.

O autor e a personagem na atividade estética. In:

Paulo Bezerra. 5. ed. São Paulo: Martins Fontes, 2010a. p. 3-186.

Estética da criação verbal. Trad.

O problema do texto na lingüística, na filologia e em outras ciências humanas. In: BAKHTIN,

M. Estética da criação verbal. Trad. Paulo Bezerra. 5. ed. São Paulo: Martins Fontes, 2010b. p. 307-336. Os gêneros do discurso. In:

Paulo: Martins Fontes, 2010c. p. 261-306.

Estética da criação verbal. Trad. Paulo Bezerra. 5. ed. São

Para uma filosofia do ato responsável. Trad. de Valdemir Miotello E Carlos Alberto Faraco. São Carlos: Pedro \& João Editores, 2012.

2009.

(VOLOCHÍNOV). O freudismo: um esboço crítico. Trad. Paulo Bezerra. São Paulo: Perspectiva,

BERZUKOV, F. D; GORBUNOV D; SHAPOSHNIKOV, M. On initial conditions for the Hot Big

Bang. Journal of Cosmology and Astroparticle Physics, p. 1-40, Jun. 2009.

BLOM, J. N; HANSEN, K. R. Click bait: Forward-reference as lure in online news headlines. Journal of Pragmatics, n.76, p. 87-100, 2015.

BLOOR, A. J. A cognitive model of fiction writing. 1997. 564f. Thesis (PhD Philosophy) - Middlesex University, London, 1997.

BOLTER, J. D. The Rhetoric of Interactive Fiction. In: COHEN, P. G. (Ed.). Texts and Textuality: Textual Instability, Theory, and Interpretation. New York/London: Garland Publishing, 1997. p. 269-290. BUMGARNER, B. A. You have been poked: Exploring the uses and gratifications of Facebook among emerging adults. First Monday, v.12, n.11, p. 1-10, 2007.

BUSH, V. As we may think. The Atlantic, p.1-8, jul. 1945.

CABRAL, C. G; BAZZO, W. A.. As mulheres nas escolas de engenharia brasileiras: história, educação e futuro. Revista de Ensino de Engenharia, v. 24, n. 1, p. 3-9, 2005.

CAPRA, F. The Tao of Physics. Colorado: Shambhala, 1975.

CHEEVER, J. The Stories of John Cheever. New York: Vintage Books, 2000.

CHOPRA, D. Quantum Healing: Exploring the Frontiers of Mind/Body Medicine. New York: Bantam, 1989.

CITELI, M. T. Mulheres nas ciências: mapeando campos de estudo. Cadernos Pagu, Campinas, n.15, p. 39-75, 2000.

DINUCCI, D. Fragmented Future. Print: Design \& New Media, 1999.

LEDERMAN, L; TERESI, D. The God particle: If the universe is the answer, what is the question? Boston, New York: Houghton Mifflin Harcourt, 2006.

HEATH, C; HEATH, D. Made to stick: Why some ideas survive and others die. Random House, 2007.

GRILLO, S. V. C. Divulgação científica: linguagens, esferas e gêneros. 2013. 333f. Tese (Livre Docência em Filologia e Língua Portuguesa) - Faculdade de Filosofia, Letras e Ciências Humanas, Universidade de São Paulo, São Paulo, 2013.

GOLBECK, J. Analyzing the social web. Waltham: Elsevier, 2013.

GOSWAMI, A. The Self-Aware Universe: How Consciousness Creates the Material World. New York: G. P. Putnam's Sons, 1993.

MINELLA, L. S. Temáticas prioritárias no campo de gênero e ciências no Brasil: raça/etnia, uma lacuna? Cadernos Pagu, Campinas, n. 40, p. 95-140, jan./jun. 2013.

MALHOTRA, A.; MALHOTRA, C. K; SEE, A. How to create brand engagement on Facebook. MIT Sloan Management Review, Cambridge, v. 54, n. 2, p.18-20, 2013.

MORRIS, D. et al. Gestures, their origins and distribution. New York: Stein and Day, 1979. 
MOULTHROP, S. Rhizome and resistance: Hypertext and the dreams of a new culture. In: LANDOW, G. (Ed.) Hyper/text/theory. Baltimore: Johns Hopkins University Press, 1994. p. 299-322.

NELSON, T. H. The hypertext. In: Proceedings of the world Documentation Federation, p. 84-100, out. 1965

PEARLMAN, L. I like this. The Facebook Blog, 10 de fevereiro, 2009. Disponível em: $<$ http://blog.facebook.com/blog.php?post=53024537130> e <https://www.facebook.com/notes/facebook/i-like-this/53024537130/>. Acesso em: 4 jun. 2017.

RAPKIEWICZ, C. E. Informática: domínio masculino? Cadernos Pagu, Campinas, n.10, p.169-200, 1998.

STENGER, V. J. Quantum quackery. Skeptical Inquirer, v. 21. n. 1, p. 37, 1997.

SHERZER, J. The Brazilian thumbs-up gesture. Journal of Linguistic Anthropology, v.1, n.2, p. 189-197, 1991.

VOLÓCHINOV, V. Marxismo e Filosofia da Linguagem. Trad. Sheila Grillo e Ekaterina Américo. São Paulo: Edições 34, 2017.

\section{Recebido em: 16/12/17. Aprovado em: 29/07/18.}

Title: The Act of Liking: The standardization of responsiveness on Facebook Author: Artur Daniel Ramos Modolo

Abstract: This article analyzes posts published by pages of Brazilian popular science on Facebook, based on the concept of responsiveness from the Bakhtinian theory. Due to the fact that social networking sites provide standardized and quantifiable means of responsive forms, part of the consequences produced by this type of online interactivity is investigated. Qualitative and quantitative data of the analyzed corpus are combined to produce an interpretation about the act of liking on Facebook. All publications were collected during four months of publication by the pages of Pesquisa FAPESP, Scientific American Brasil and Superinteressante. As a result, it is possible to identify discursive and thematic characteristics of the posts that obtained the greatest repercussion among the readers, as well as to establish relations between the hypertextual reading, web 2.0 and the responsive forms produced in this context.

Keywords: Responsiveness. Dialogical analysis. Social networking. Standardization. Facebook.

Título: El acto de le dar un me gusta: la estandarización de la respuesta en el Facebook Autor: Artur Daniel Ramos Modolo

Resumen: Este artículo analiza publicaciones hechas por páginas de divulgación científica brasileña en Facebook, tomándosele como base el concepto de respuesta proveniente de la teoría de Bajtín. En virtud de las redes sociales pusieren disponibles medios estandarizados y cuantificables de formas de respuestas, investiga parte de las consecuencias producidas por ese tipo de interactividad en línea. Concilia datos cualitativos y cuantitativos del corpus analizado para producir una interpretación sobre el acto de dar un me gusta en Facebook. Como material, coleccionó todas las publicaciones, durante cuatro meses, de las páginas de Pesquisa FAPESP, Scientific American Brasil y Superinteressante. El resultado permite identificar características discursivas y temáticas de los posts que obtuvieron mayor repercusión entre los lectores, así como establecer relaciones entre la lectura hipertextual, la web 2.0 y las formas de respuestas producidas en ese contexto.

Palabras clave: Respuesta. Análisis dialógico. Redes sociales. Estandarización. Facebook.

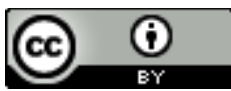

Este texto está licenciado com uma Licença Creative Commons Atribuição 4.0 Internacional. 